\title{
Integrated remotely tunable optical delay line for millimeter- wave beam steering fabricated in an InP generic foundry
}

Citation for published version (APA):

Cao, Z., Tessema, N. M., Latkowski, S., Zhao, X., Chen, Z., Moskalenko, V., Williams, K. A., Boom, van den, H. P. A., Tangdiongga, E., \& Koonen, A. M. J. (2015). Integrated remotely tunable optical delay line for millimeterwave beam steering fabricated in an InP generic foundry. Optics Letters, 40(17), 3930-3933.

https://doi.org/10.1364/OL.40.003930

\section{Document license:}

TAVERNE

DOI:

10.1364/OL.40.003930

Document status and date:

Published: 01/01/2015

\section{Document Version:}

Publisher's PDF, also known as Version of Record (includes final page, issue and volume numbers)

\section{Please check the document version of this publication:}

- A submitted manuscript is the version of the article upon submission and before peer-review. There can be important differences between the submitted version and the official published version of record. People interested in the research are advised to contact the author for the final version of the publication, or visit the $\mathrm{DOI}$ to the publisher's website.

- The final author version and the galley proof are versions of the publication after peer review.

- The final published version features the final layout of the paper including the volume, issue and page numbers.

Link to publication

\section{General rights}

Copyright and moral rights for the publications made accessible in the public portal are retained by the authors and/or other copyright owners and it is a condition of accessing publications that users recognise and abide by the legal requirements associated with these rights.

- Users may download and print one copy of any publication from the public portal for the purpose of private study or research.

- You may not further distribute the material or use it for any profit-making activity or commercial gain

- You may freely distribute the URL identifying the publication in the public portal.

If the publication is distributed under the terms of Article $25 \mathrm{fa}$ of the Dutch Copyright Act, indicated by the "Taverne" license above, please follow below link for the End User Agreement:

www.tue.nl/taverne

Take down policy

If you believe that this document breaches copyright please contact us at:

openaccess@tue.nl

providing details and we will investigate your claim. 


\title{
Integrated remotely tunable optical delay line for millimeter-wave beam steering fabricated in an InP generic foundry
}

\author{
Z. Cao, * N. Tessema, S. Latkowski, X. Zhao, Z. Chen, V. Moskalenko, K. A. Williams, \\ H. P. A. van der Boom, E. Tangdiongga, and A. M. J. Koonen \\ COBRA Institute, Eindhoven University of Technology, NL 5600 MB Eindhoven, The Netherlands \\ *Corresponding author: z.cao@tue.nl
}

Received 22 May 2015; revised 15 July 2015; accepted 20 July 2015; posted 30 July 2015 (Doc. ID 241358); published 17 August 2015

\begin{abstract}
A compact and fabrication-tolerant integrated remotely tunable optical delay line is proposed for millimeter-wave beam steering and is fabricated in an InP generic foundry. The proposed delay line is based on a spectrally cyclic-arrayed waveguide grating feedback loop. Its major features include the tolerant architecture with reduced chip size, and bi-directional operation with simplified remote tuning. Moreover, its cyclic feature guarantees further cascaded operations either for 2D radio beam steering or for highresolution delay generation. The experimental results show less than 6.5-dB insertion loss of the integrated delay line. Five different delays from 0 to 71.6 ps are generated with less than 0.67-ps delay errors. (๑) 2015 Optical Society of America
\end{abstract}

OCIS codes: (060.5625) Radio frequency photonics; (250.5300) Photonic integrated circuits; (050.2770) Gratings.

http://dx.doi.org/10.1364/OL.40.003930

The current explosion of communication traffic volume is driven by an insatiable appetite for high-speed internet connectivity and video-based content delivery to wireless and mobile terminal users, especially for in-home scenarios. A lot of research has been carried out to expand wireless capacity via spatial techniques. Unlike spatial multiplexing, which requires complicated digital signal processing, radio beam steering (BS), which is sometimes referred to as spatial filtering, directs signals to the desired users with minimum interference. Optical true-time delay is widely used for broadband radio-beam steering to avoid the beam squint problems [1-7]. Recently, radio-overfiber systems incorporating optical true-time-delay radio-beam steering have been proposed for in-home networks [3,4]. However, current optical tunable delay lines (OTDLs) based on bulk-optics components limit their further applications $[8,9]$. An integrated OTDL with remote control can reduce the complexity of radio access points, which matches the centralization nature of beam-steered RoF systems. Historically, there are mainly two approaches to realize the integrated OTDLs. The first is based on physical length-induced delay $[1,10,11]$, and the second is based on optical filtering-induced group delay [12-16]. As a representative example of the first kind, an optical radio-beam steering chip with wavelength (de-)multiplexer, discrete delay lines, and Mach-Zehnder interferometer (MZI) switch was proposed by Soares et al. in [10]. In this chip, an arrayed waveguide grating (AWG) is used as a (de-) multiplexer for wavelength separation. Delays for different antennas are generated on a wavelength basis, and the delays are step-wise tuned by a 3-stage MZI-switch. In general, the first kind of integrated OTDLs can provide broadband but step-wise tunable delays. The angular resolution of a radio beam then depends on the step number. The second one can provide continuous tuning of group delay based on all-pass filters. Madsen and co-workers explored the possibility to use optical ring resonators (ORRs) as all-pass filters [15,16], and an elegant theoretical analysis framework based on digital filter concept was proposed and developed [17]. Later, Zhuang et al. demonstrated a prototype of integrated OTDLs of multiple ORRs [12]. However, such an approach suffers the narrow operation bandwidth limited by the inherent feature of filter resonation. Cascaded ORRs can overcome such limitation to some extent but at the expense of large chip area and complicated trimming [18]. In a word, the first kind of integrated OTDLs are suitable for broadband applications with low angular resolution, while the second one matches the narrowband applications desiring relatively higher angular resolutions. In-home communication is usually with very high throughput and limited space (thus results in low angular resolution), which makes the first kind of integrated OTDL suitable for such applications. Arrayed waveguide-grating feedback loop (AWG-loop) is a good option [19]. To allow twodimensional (2D) squint-free radio-beam steering by means of single-parameter tuning, we proposed the concept of spectralcyclic AWG-loop (SC-AWG-loop) for 2D radio beam steering. In this Letter, we realize and demonstrate an integrated spectralcyclic arrayed waveguide-grating feedback loop (SC-AWG-loop) through the generic-foundry-based InP platform from PARADIGM project. The photonic integrated circuit (PIC) was fabricated with its successful yielding in the first run. The insertion loss (IL) of our PIC including the two travels through the SC-AWG is less than $6.5 \mathrm{~dB}$ with 1.8 -dB flatness, which allows operations with high dynamic range. 

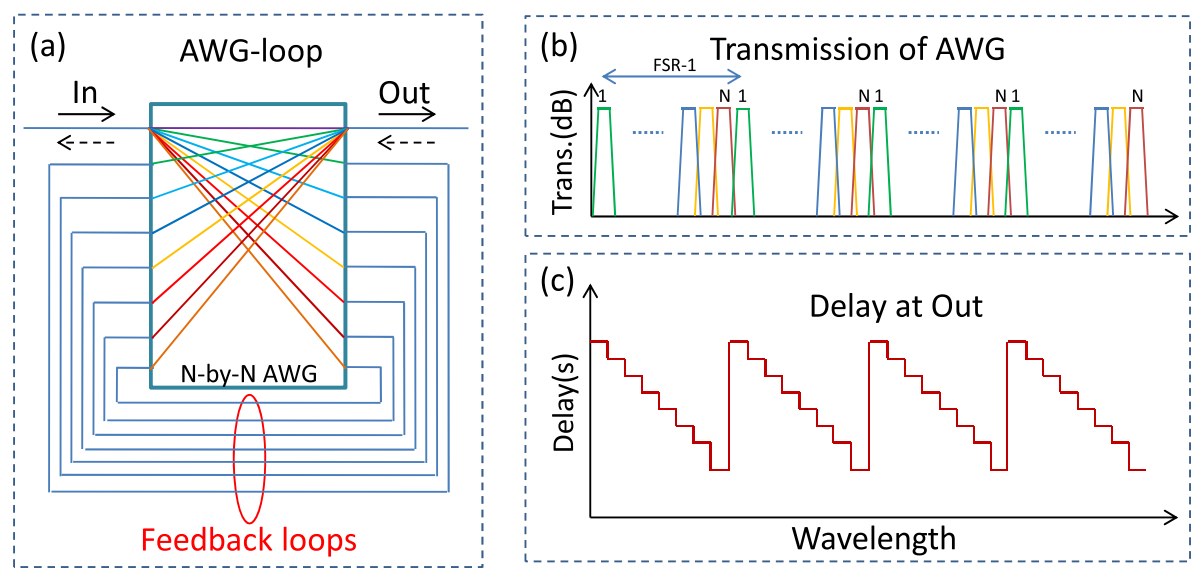

Fig. 1. Principle of proposed AWG-loop-based integrated optical tunable delay line (OTDL). (a) the AWG-loop; (b) 1-by-2 optical delay network; (c) the spectral transmission of an N-by-N cyclic AWG; (d) and (e) the delay at Out-2/-1 of (b). OS, optical splitter.

The integrated SC-AWG-loop is schematically shown in Fig. 1(a). A fiber system using a discrete AWG component and fiber delay lines has been demonstrated [1] for 10-40$\mathrm{MHz}$ operation. Due to its bulk size, such a system can only work properly for large delays (and results in low operational frequency) with low delay accuracy. There are two main advantages of the proposed integrated SC-AWG-loop. The first is that the AWG is designed to be spectral-cyclic, which allows the interleaved operation as discussed in [20]. The second is that the integrated SC-AWG-loop with small footprint enables short delays with high accuracy, which suits high-frequency operation like at mm-wave bands. As shown in Fig. 1(a), the Nby-N SC-AWG functions both as a wavelength multiplexer (MUX) and de-multiplexer (de-MUX). Its spectral transmission is schematically shown in Fig. 1(b). The feedback loops (optical waveguides) connect $\mathrm{N}-1$ pairs of inputs and outputs in a symmetric configuration for recirculating operations and leave one pair for the external input and output. This SCAWG-loop is topologically equivalent to two AWGs in series with a delay element in between, which works as a step-wise OTDL. As shown in Fig. 1(c), an optical signal through the SC-AWG-loop can be stepwisely tuned with its wavelength tuning. The delay number and resolution depend on the number of AWG inputs and outputs, which can be made as large as a thousand. There are some advanced features of the proposed SC-AWG-loop. First, by reusing the same AWG as MUX and de-MUX, its footprint can be significantly reduced (approximately by half). Moreover, its fabrication tolerance is enhanced since the spectral misalignment does not exist for the identical MUX and de-MUX. Third, it can support delay tuning with remote wavelength tuning, which enables a centralized and simple network. Finally, it can simultaneously support bi-directional operations. As shown in Fig. 1(a), the solid and dash arrows denote left-to-right and the opposite operations, respectively. Such operations are highly demanded for telecom systems including up- and down-links. By reusing one device, the footprint and stability can benefit.

The integrated circuit is fabricated on a 3-in. InP wafer with $500 \mu \mathrm{m}$ thickness (which is thinned down to $250 \mu \mathrm{m}$ after processing). There are two types of waveguide cross-sections employed in our design: a low-index-contrast waveguide cross-section E200 (200 nm etch) and a high-index-contrast one E1700 (1700 nm etch). E200 is with low-loss for AWG free-propagation regions (FPRs), while E1700 with small radius is for waveguide connections. A generic foundry approach for the device design and fabrication is employed inside the framework of PARADIGM project [21]. Comparing with discrete component $[22,23]$ and photonics crystal [24], such designs can be fully integrated [25].

The core component for the SC-AWG-loop is a cyclic 5-by5 AWG. The mask layout and photo of the test structure of the AWG are shown in Fig. 2(a). The spectrum centre of the AWG $\left(\lambda_{c}\right)$ is designed at $1550 \mathrm{~nm}$, and the grating order is designed to be 174. Its free spectral range (FSR) is $8 \mathrm{~nm}(1000 \mathrm{GHz})$ with $1.6-\mathrm{nm}(200-\mathrm{GHz})$ channel spacing (CS). Five spot-size convertors (SSCs) are used to allow better lateral fiber coupling. The measurement setup of the AWG is shown in Fig. 2(b). 16.9- $\mathrm{dBm}$ amplified spontaneous emission (ASE) noise from an EDFA is launched into a polarization beam splitter to allow the pure TE or TM polarization of the ASE noise. The cleaved single-mode fiber $(\mathrm{CF})$ is employed for lateral optical coupling. A polarization controller (PC) is employed to adjust the polarization of the injected optical signal aligned with the TE mode of the input SSC [In-0 marked in Fig. 2(a)]. The waveguide connecting In- 0 is located at the middle of the input FPR. The other cleaved fiber is used to collect the optical signal from the outputs (Out-0-Out-4) shown in Fig. 2(a). An optical spectrum analyzer (OSA) with a resolution of $0.02 \mathrm{~nm}$ is used to record the measured results. The coupling loss of the SSCs is $1.75 \mathrm{~dB}$ per facet. The waveguide loss of E1700 is $1.25 \mathrm{~dB} / \mathrm{cm}$ for TE mode. The measured spectral transmission of the AWG is shown in Fig. 2(c). The optical link including the polarization controller introduces around 2-dB loss. The ASE noise is first launched into a waveguide test structure and is then recorded by the OSA as a reference for further calibration. The Out-2 waveguide of the AWG test structure is damaged, which results in the missing of the transmission of Out-2 in Fig. 2(c). The measured spectral center of Out-2 (measured $\left.\lambda_{c}\right)$ is at $1546.8 \mathrm{~nm}$. The IL of the AWG is better than $2.8 \mathrm{~dB}$, and the IL difference of all channels is less than $0.9 \mathrm{~dB}$. The crosstalk is measured better than $25 \mathrm{~dB}$. An FFT operation of the measured spectral transmission data is performed, which indicates the 8-nm FSR and the 1.6-nm CS. The $0.52 \mathrm{~nm}-3 \mathrm{~dB}$ pass-bands are obtained for all channels, 

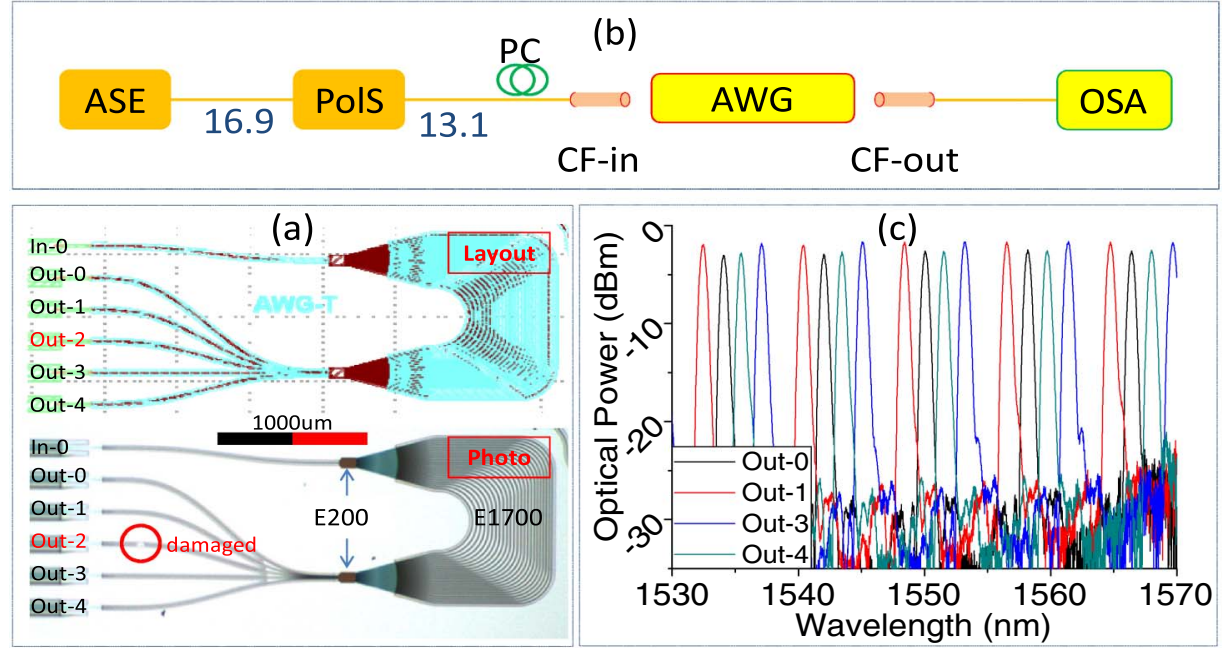

Fig. 2. (a) The mask layout and photo of the AWG test structure, (b) the measurement setup, and (c) the measured spectral transmission of the AWG.

which means $65-\mathrm{GHz}$ electrical bandwidth for radio signals. The cyclic-spectral feature is clearly observed in Fig. 2(c).

The measurement setup of the SC-AWG-loop is shown in Fig. 3(a). The 12.9-dBm optical carrier from a tunable laser passes to a Mach-Zehnder modulator (MZM) via a PC. An electrical pulse with 500-ps duration generated from an electrical arbitrary waveform generator (E-AWG) is amplified by a $12-\mathrm{GHz}$ electrical amplifier with a $19-\mathrm{dB}$ gain (SHF100APP) to drive the MZM. The modulated optical signal with 2.6- $\mathrm{dBm}$ power is then launched to the input of the SC-AWG-loop (In-0) via a cleaved fiber. A PC is used to align the polarization to the TE mode of waveguides in the SC-AWG-loop. Another cleaved fiber is employed to collect

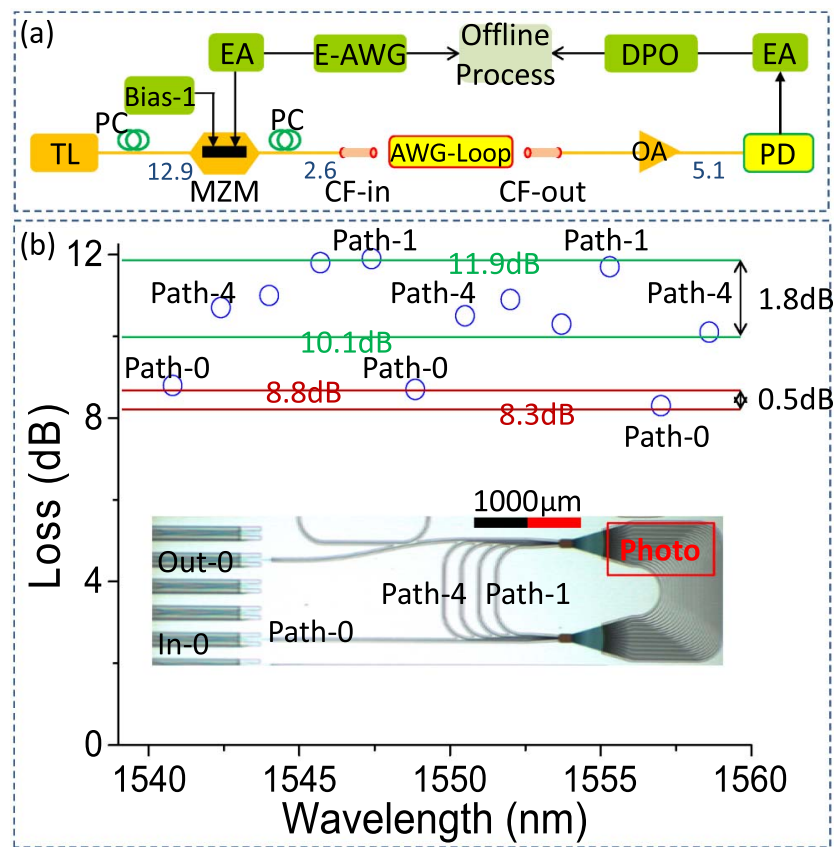

Fig. 3. Measurement of the proposed AWG-loop, (a) the measurement setup; (b) time domain correlation for delay measurement. the output optical signal. With an EDFA [OA shown in Fig. 3(a)], the collected optical signal is amplified to $5.1 \mathrm{dBm}$ before illuminating a $40-\mathrm{GHz}$ photodiode $(\mathrm{u} 2 \mathrm{t})$. The detected electrical signal is then amplified by an EA (SHF100APP) and is further sampled by a digital phosphor oscilloscope (Tektronix DPO70000) with an equivalent-time sampling mode. The oscilloscope is locked to the E-AWG by a 10$\mathrm{MHz}$ reference clock. The sampling rate is $2.5 \mathrm{TS}$ aps, and thus the time resolution is $400 \mathrm{fs}$. The sampled signal is then offline processed to obtain the delays based on the time-domain correlation method. The photo of the SC-AWG-loop under test is shown as an inset of Fig. 3(b). A 5-by-5 cyclic AWG identical to a previously measured one is used in the SC-AWG-loop. The waveguides connect four pairs of input and output to form the feedback loops with different delays. One pair of input and output of the AWG (In-0, Out- 0 ) is used as the input and output of the SC-AWG-loop and is connected to two SSCs. The maximum delay (Path-4) is designed to be 12.5 ps for $\pi$ phase shift at $40 \mathrm{GHz}$. The designed delays of Path-1 to Path- 4 are progressively increased from 0 to 12.5 ps.

The loss of one open path (Path- 0 ) and four feedback loop paths (Path-1 to -4) is measured as shown in Fig. 3(b). The 3.5- $\mathrm{dB}$ coupling loss $(1.75 \mathrm{~dB}$ per facet) and 2-dB link loss are taken into account. The tunable laser (TL) is employed to provide fine-tuning of the wavelength for the transmission peak searching. For the loss measurement, the MZM and OA are bypassed, and the OSA is replaced by an optical power meter. The measured results show that the loss for all channels is less than $11.9 \mathrm{~dB}$. Subtracting $5.5 \mathrm{~dB}$ off-chip loss, the measured results show 6.4-dB loss, which is comprised of twice the AWG IL and the loss of waveguides in between. Such IL is acceptable for many microwave photonics applications. Considering the $1-\mathrm{dB}$ waveguide loss, and the $2.8-\mathrm{dB}$ IL measured from the AWG test structure, the measured IL of the SCAWG-loop exhibits a high consistency with its test structure counterpart. For Path- 0 , since it travels the AWG only once, its IL is less $8.8 \mathrm{~dB}$. A 3.1-dB averaged loss reduction is observed for Path- 0 compared with the others. Path- 1 to Path- 4 exhibit higher loss because of an extra AWG travel. Due to the 


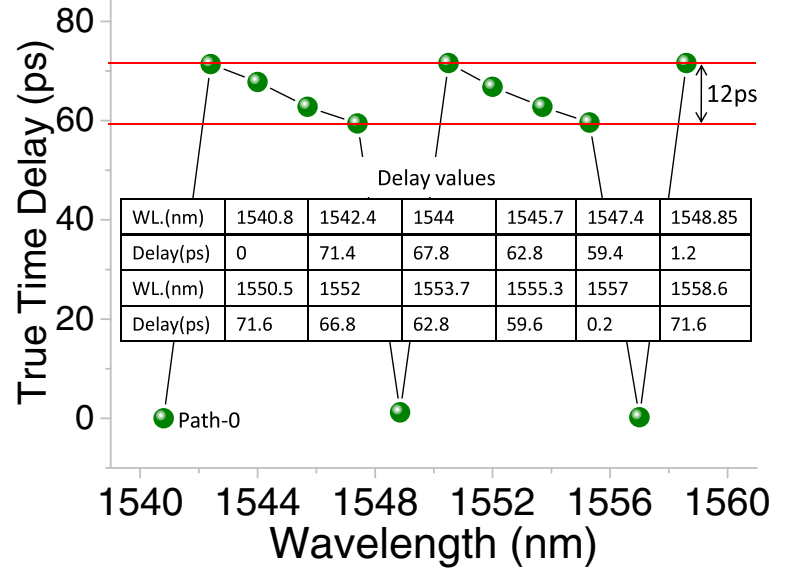

Fig. 4. Measured delays of different delay channels of the AWG-loop.

cyclic feature of the AWG, the loss also exhibits the cyclic feature. The loss variation of Path- 0 is less than $0.5 \mathrm{~dB}$, while the ones of Path- 1 to Path- 4 are less than $1.8 \mathrm{~dB}$. The measured $\lambda_{c}$ is $1547.4 \mathrm{~nm}$ (Path-1), suggesting a 0.6-nm spectral offset from the AWG test structure. However, such spectral offset does not induce any misalignment, because the MUX and de-MUX are the same one in the feedback loop configuration.

The sampled signal traveling from Path- 0 is used as a reference signal for delay measurement. The cross-correlation is performed between the reference signal and the others. Path- 0 can be found based on the minimum loss as indicated in Fig. 3(b). For the wavelengths directly traveling from In- 0 to Out- 0 (Path-0), the total delay is equal to the cross delay of the AWG (AWG-delay). For other wavelengths going through the feedback loops, the total delay includes twice the AWG-delay plus the delay of the feedback loops (loop-delay). Thus, we can see the four progressive delays and also one "fall-down" delay (Path-0) shown in Fig. 4. As shown in Fig. 4, the linear delays are exhibited for Path-1 to Path-4 with 12-ps delay, which is a little smaller than the delay (12.5 ps) we designed. This could be induced by the limited time resolution ( $400 \mathrm{fs}$ ) of the DPO. The detailed delay values are also indicated in the inset table of Fig. 4. The differences between the designed delays and the measured ones for Path- 1 to Path- 4 are $-0.5,0.1,-0.76$, and 0 ps from 1540 to $1548 \mathrm{~nm}$. And the delays of the same paths but at different wavelengths from Path- 1 to Path- 4 are $0.2,-1,0$, and $0.2 \mathrm{ps}$. The acceptable matches between the designed delays and measured ones demonstrate the high design accuracy.

To conclude this Letter, we propose an integrated broadband optical tunable delay line based on the cyclic AWG feedback loop for mm-wave beam steering. The experimental results show less than $6.5-\mathrm{dB}$ IL of the integrated SCAWG-loop. Five different delays from 0 to 71.6 ps are generated with less than 0.67 -ps delay errors.

Funding. European Research Council (ERC) (Advanced Grant BROWSE, Advanced Grant PARADIGM); Technologiestichting STW (Technology Foundation STW) (FREEBEAM).

Acknowledgment. We would like to thank Phoenix Software and Bright Photonics for providing the design kit,
AWG module, and design support. Z. Cao thanks Dr. X. Leijtens and Dr. E. Smalbrugge from TU/e, and Dr. F. M. Soares from HHI for necessary measurement support.

\section{REFERENCES}

1. S. Yegnanarayanan, P. D. Trinh, and B. Jalali, Opt. Lett. 21, 740 (1996).

2. O. Raz, S. Barzilay, R. Rotman, and M. Tur, J. Lightwave Technol. 26, 2774 (2008)

3. J. Yao, J. Yang, and Y. Liu, IEEE Photon. Technol. Lett. 14, 687 (2002).

4. L. Jofre, C. Stoltidou, S. Blanch, T. Mengual, B. Vidal, J. Marti, I. Mckenzie, and J. M. del Cura, IEEE Trans. Antennas Propag. 56, 1594 (2008).

5. B. Vidal, T. Mengual, C. Ibanez-Lopez, and J. Marti, IEEE Photon. Technol. Lett. 18, 2590 (2006).

6. M. A. Piqueras, G. Grosskopf, B. Vidal, J. Herrera, J. M. Martinez, P. Sanchis, V. Polo, J. L. Corral, A. Marceaux, J. Galiere, J. Lopez, A. Enard, J.-L. Valard, O. Parillaud, E. Estebe, N. Vodjdani, C. MoonSoon, J. H. den Besten, F. M. Soares, M. K. Smit, and J. Marti, IEEE Trans. Microwave Theory Tech. 54, 887 (2006).

7. B. Vidal, J. L. Corral, M. A. Piqueras, and J. Marti, IEEE J. Sel. Top. Quantum Electron. 8, 1202 (2002).

8. Z. Cao, F. Li, A. Reniers, C. W. Oh, H. van den Boom, E. Tangdiongga, and A. M. J. Koonen, IEEE Photon. Technol. Lett. 26, 575 (2014).

9. Z. Cao, R. Lu, Q. Wang, N. Tessema, Y. Jiao, H. P. A. van den Boom, E. Tangdiongga, and A. M. J. Koonen, Opt. Lett. 39, 3402 (2014).

10. F. M. Soares, F. Karouta, E. Smalbrugge, M. K. Smit, J. J. M. Binsma, J. Lopez, A. Enard, and N. Vodjdani, "An InP-based photonic integrated beamformer for phased array antennas," in Optical Amplifiers and Their Applications/Integrated Photonics Research (OATA/IPR2004), San Francisco, California, 2014, paper IFB2.

11. R. G. Broeke, C. Jin, J. Chen, S. Sang-Woo, D. Yixue, N. K. Fontaine, B. Jong-Hwa, J. Yan, F. M. Soares, F. Olsson, S. Lourdudoss, A.-V. H. Pham, M. Shearn, A. Scherer, and S. J. B. Yoo, IEEE J. Sel. Top. Quantum Electron. 13, 1497 (2007).

12. L. Zhuang, C. G. H. Roeloffzen, R. G. Heideman, A. Borreman, A. Meijerink, and W. van Etten, J. Lightwave Technol. 28, 19 (2010).

13. L. Zhuang, C. G. H. Roeloffzen, R. G. Heideman, A. Borreman, A. Meijerink, and W. van Etten, IEEE Photon. Technol. Lett. 19, 1130 (2007).

14. M. S. Rasras, C. K. Madsen, M. A. Cappuzzo, E. Chen, L. T. Gomez, E. J. Laskowski, A. Griffin, A. Wong-Foy, A. Gasparyan, A. Kasper, J. Le Grange, and S. S. Patel, IEEE Photon. Technol. Lett. 17, 834 (2005).

15. G. Lenz, B. J. Eggleton, C. K. Madsen, and R. E. Slusher, IEEE J. Quantum Electron. 37, 525 (2001).

16. C. K. Madsen and G. Lenz, IEEE Photon. Technol. Lett. 10, 994 (1998).

17. C. K. Madsen, J. Lightwave Technol. 18, 860 (2000).

18. A. Meijerink, C. G. H. Roeloffzen, R. Meijerink, L. Zhuang, D. A. I. Marpaung, M. J. Bentum, M. Burla, J. Verpoorte, P. Jorna, A. Hulzinga, and W. van Etten, J. Lightwave Technol. 28, 3 (2010).

19. N. K. Fontaine, R. P. Scott, C. Yang, D. J. Geisler, J. P. Heritage, K. Okamoto, and S. J. B. Yoo, Opt. Lett. 33, 1714 (2008).

20. T. Koonen and Z. Caol, "Optically controlled $2 \mathrm{D}$ radio beam steering system," in 2014 International Topical Meeting on Microwave Photonics (MWP) and the 2014 9th Asia-Pacific Microwave Photonics Conference (APMP), Sapporo, Japan, October 20-23, 2014, pp. 389-391.

21. PARADIGM project, http://www.paradigm.jeppix.eu/.

22. S. Huang, J. Li, Y. Ye, P. Shi, J. Zhou, B. Guo, and W. Gu, Opt. Laser Technol. 44, 776 (2012).

23. P. Berger, J. Bourderionnet, F. Bretenaker, D. Dolfi, and M. Alouini, Opt. Express 19, 21180 (2011).

24. J. Sancho, J. Bourderionnet, J. Lloret, S. Combrié, I. Gasulla, S. Xavier, S. Sales, P. Colman, G. Lehoucq, D. Dolfi, J. Capmany, and A. Rossi, Nat. Commun. 3, 1075 (2012).

25. L. Zhuang, M. Hoekman, W. Beeker, A. Leinse, R. Heideman, P. Dijk, and C. Roeloffzen, Laser Photon. Rev. 7, 994 (2013). 